\title{
A viagem de um leitor: uma investigação semiótica do processo de leitura
}

\author{
Ana Carolina Cortez NORONHA-TADDEI (UNESP)
}

RESUMO: Este trabalho tem por objetivo investigar o processo de leitura. Nosso corpus de análise será uma narrativa que ficcionaliza esse processo, comparando-o a uma viagem. Para a investigação da construção do sentido no texto e para se pensar leitura como processo discursivo utiliza-se a teoria semiótica greimasiana.

PALAVRAS-CHAVE: Semiótica Greimasiana, leitura, processo de leitura, lingüística.

ABSTRACT: The aim of this paper is to investigate reading as a process. Our corpus is composed by a narrative which brings this process as a fiction, comparing it to a trip. The French Semiotics theory is used to investigate how meaning is built and to conceive reading as a discursive process.

KEYWORDS: French Semiotics, reading, reading process, linguistics. 
Ao final do meu curso de especialização, em 2002, saí em busca de um objeto de investigação com o qual pudesse produzir a monografia de conclusão de curso. A sugestão do livro Por onde você andou, Robert?, de Hans Magnus Enzensberger, me foi dada com o objetivo de nele observar o passeio de um indivíduo pela história e, a partir desse passeio histórico, identificar as mudanças narrativas que se operavam nesse sujeito que se constituía enquanto observador. Nesse tempo eu tinha um contato mais estreito com a $\mathrm{AD}$ francesa e nenhum contato com a semiótica. Por esse motivo a observação de um sujeito histórico fazia-se bastante pertinente. Ao mesmo tempo em que fui desenvolvendo minha pesquisa, aconteceu também um contato mais estreito com livros sobre leitura - primeiramente Chartier, depois Marisa Lajolo e, finalmente, a leitura vista a partir da teoria semiótica do texto, através do trabalho do professor Arnaldo Cortina. A partir dessas leituras apontou-se para mim um paralelo entre as viagens do protagonista Robert e o que poderia se chamar de leitura, pensando-a como um processo de apreensão de sentidos.

É do senso comum pensar que um leitor "viaja" enquanto lê, porque transportase para espaço e tempo diversos do seu, percebe esses espaço e tempo, interage com ele e seus atores e, ao final, modifica-se de algum modo em função desse novo saber. Ao tomar leitura como sinônimo de viagem, pensa-se em um sujeito que "mergulha" em um mundo que lhe é novo e que se lhe abre para a observação, para o conhecimento. Cabe ao leitor decifrar, através de um código escrito do qual possui conhecimento prévio, o novo, ao mesmo tempo em que cabe ao viajante decifrar, pela observação confrontada com as informações prévias que possui, os elementos que se apresentam. Na narrativa escolhida como corpus, Robert não só mergulha em suas viagens - ele literalmente "entra" no mundo que lê -, como também volta no tempo, o que pode ser interpretado como o percurso da busca do conhecimento, uma vez que se faz necessária, durante esse processo, a busca de suas fontes, sua inspiração, seus mentores etc. A personagem passeia por lugares e momentos dos quais já tinha, histórica ou geograficamente, ouvido falar. Daí sua leitura, histórica, confrontada com o testemunho ocular que ele faz da situação, que aqui também chamamos de leitura. Foi, portanto, a questão do passeio pela história, durante o qual a personagem é obrigada a identificar determinada situação para interagir com ela ('ler' a situação) que pensei em utilizar esse corpus para investigação do processo de leitura, 'apreensão do sentido por um sujeito-leitor' .

Uma outra questão que se faz pertinente a este trabalho, e que justifica a escolha do corpus, é procurar o enunciador que se dirige ao enunciatário, de outro modo, identificar o objeto-valor que o enunciador que constrói a narrativa de Robert destina ao enunciatário dessa narrativa, classificada como juvenil. A narrativa é construída tendo como personagem principal um adolescente do final do século XX. Apresentado como um menino ausente, que se interessa mais pelas imagens que vê a partir de manchas em sua visão do que pelo mundo exterior, a construção desse personagem pode ser vista como uma crítica aos adolescentes que vivem centrados em seu próprio mundo. A partir do momento que Robert entra nas imagens que vê, é obrigado a interagir com esse mundo que lhe é apresentado, não podendo mais estar alheio a ele ou dele ausente. Em um momento de sua primeira viagem tem um sonho no qual vê a mãe e sua professora chamando-o de "menino distraído, menino ausente". Ele 
constata, então, que, naquele momento, estava literalmente ausente do seu mundo de origem - de corpo e alma. Mas enquanto sujeito ausente de seu mundo real, a Alemanha do final do século XX, Robert se torna presente num outro mundo, do qual não pode (ou não quer) abstrair-se. Não existe mais, para ele, aquela possibilidade de se fazer presente em corpo, apenas, e estar ao mesmo tempo distraído, situado "num outro mundo". Pensado dessa maneira, o objeto-valor que a narrativa doa a seu enunciatário é uma crítica a essa "ausência" típica da adolescência, em especial no tempo em que é produzida.

Pode-se também ver a doação de um objeto-valor didático ao enunciatário dessa narrativa: o valor da aprendizagem da história e das línguas. Robert é obrigado a viver em períodos da história sobre os quais teve algumas informações durante as aulas da escola. São poucas, porém ajudam-no a interagir com os diferentes mundos para os quais é transportado. E também valoriza as línguas estrangeiras que aprendeu, seu contato com dicionários e outras maneiras, anteriores, de interação com outra língua, que lhe conferem maior competência para aprender novas.

A narrativa "Por onde você andou, Robert?" pode ser considerada como uma metáfora da leitura, pois ao apresentar um sujeito que viaja para as imagens que lhe são enviadas por seus olhos, permite o estabelecimento de comparação com um leitor, que também viaja a partir daquilo que seus olhos lhe apresentam.

Continuando a justificar o enfoque deste trabalho, posteriormente à leitura inicial dessa narrativa e de uma primeira análise, regida sob a ótica da $\mathrm{AD}$ francesa, tive contato com a teoria semiótica do texto. A partir desse momento estruturou-se melhor o que compreendo como apreensão do sentido do texto, e não consigo mais conceber essa idéia sem passar pelo fato de apreender, primeiramente, a organização interna de um texto em seus níveis de significação, tentar estabelecer os percursos pelos quais se constrói o sentido (e nesse momento a significação é dada pela leitura, principalmente se se toma leitura como apreensão do sentido). E, depois, pensar no texto como um objeto de comunicação, mediador do contato entre seu enunciador e seu enunciatário, e pensar quais os elementos que estão envolvidos aí e que se fazem essenciais para mediar essa comunicação, além de buscar nele o fazer do enunciador sobre o enunciatário, que objeto um destina ao outro.

E aqui coloca-se o plano de investigação do trabalho que se apresenta: observar a organização interna do texto como um todo, buscando a construção de sua significação. Posteriormente, e é esse o momento em que se encontra este trabalho, analisar cada uma das sete viagens da personagem principal para observar como se organizam cada uma de suas passagens, procurando nelas traços recorrentes que mostrem como se dá a apreensão de sentidos pela personagem principal, como um viajante-leitor. Ainda num outro momento pretende-se apreender, por meio da investigação dessa narrativa, a construção da personagem principal como sujeito enquanto viajante-leitor, no desenrolar da narrativa. 


\title{
Semiótica e Leitura
}

\begin{abstract}
“...o leitor, ao ler, atualiza o texto e seu sentido, de acordo ou não com suas expectativas ou previsões advindas de sua competência linguística e cultural." (Bertrand, 2003, p. 413)

"Ler é dar um sentido de conjunto, uma globalização e uma articulação aos sentidos produzidos pelas sequiências. Não é encontrar o sentido desejado pelo autor, o que implicaria que o prazer do texto se originasse na coincidência entre o sentido desejado e o sentido percebido, em um tipo de acordo cultural, como algumas vezes se pretendeu (...). Ler é, portanto, constituir e não reconstituir um sentido." (Goulemot, 2001, p.108)
\end{abstract}

Entende-se que, para ler, um sujeito precisa trazer até o texto toda sua bagagem cultural, social e histórica, confrontando-a com o texto a ser lido e apreendendo, nesse interstício, seu sentido, amparado pela organização interna do texto. A leitura é um processo discursivo e, como tal, deve ser estudada a partir de sua construção como discurso. Ela consiste no modo de apreensão do sentido de um texto por um sujeito, e é mediada por diversos fatores internos e externos ao texto, e internos e externos a ele, sujeito. Semioticamente, a leitura é concebida como processo discursivo de apreensão da significação, e o texto, compreendido como articulado em vários níveis de sentido, sendo que o mais externo deles está em contato com o mundo e, conseqüentemente, com o sujeito-leitor. O sujeito-leitor apreende o sentido de mundo através das leituras que faz. Nesse caso, ele encontra-se manifestado no personagem Robert, que é passível de observação por se tratar de uma ficção. À luz destas definições encontra-se uma relação estreita entre processo de leitura e processo de construção de sujeito, o segundo utilizando-se do primeiro como um de seus fundamentos. A estruturação interna do texto feita pela semiótica está diretamente ligada à leitura. Para Bertrand (2003), as estruturas imanentes nas formas trazem consigo convenções de uso e regras explícitas, e estas moldam as expectativas dos leitores e os ajudam a prever o conteúdo, as hipóteses e as inferências de leitura.

A semiótica também se liga com a leitura no nível discursivo do texto, o nível da manifestação, que está relacionado com o mundo exterior ao texto, o contexto. A dimensão figurativa do discurso é responsável pela relação do discurso com o mundo, à medida que "estabelece, na leitura, uma relação imediata, uma semelhança, uma correspondência entre as figuras semânticas que desfilam sob os olhos do leitor e as do mundo (...)." (Bertrand, 2003, p.29)

Segundo Cortina (2004, p. 156), (...) a leitura também pressupõe a ação de um sujeito sobre o texto lido, na medida em que ele construirá seu texto interpretativo a partir do confronto de seu conhecimento, dimensão cognitiva, sobre o fazer do outro.

$\mathrm{O}$ fato de a leitura pressupor a ação de um sujeito sobre um texto, como afirma Cortina na citação acima, é um dos motivos deste estudo que procura cruzar processo de 
leitura e processo de formação de sujeito. O sujeito-leitor é tão construtor do texto quanto o sujeito enunciador. A existência de um pressupõe a existência do outro.

\section{A narrativa "Por onde você andou, Robert?"}

Foi num dia como outro qualquer que Robert desapareceu. E o mais incrível foi que ninguém notou que ele sumiu, nem mesmo sua mãe.

Mas ainda não estamos nesse ponto da história. Robert ainda está na cozinha, sentado no seu banquinho alto, como sempre. Só a noite de verão está mais clara que de costume, e o sol projeta listras nas paredes, nos armários e no rosto da mãe dele. Listras brancas de cegar. A luz passa pelas frestas minúsculas da persiana da porta da sacada e desenha anéis irregulares por toda a parte. Robert só precisa mover a cabeça para que as agitadas manchas de luz brinquem em seu rosto e ofusquem sua vista. (Enzensberger, 1999, p. 9)

As viagens de Robert acontecem por causa das manchas que aparecem em sua visão. No início essas viagens são apenas momentos de distração durante os quais enxerga imagens em seus olhos, mas depois o personagem acaba se transportando fisicamente para essas imagens. No fragmento acima, início de toda a história, a isotopia se estabelece pela apresentação de traços semânticos de luminosidade, que pode ser também entendido como "visão confusa ou ofuscada" (que é a causa do início das viagens do menino): "verão", "noite clara", "sol", "listras brancas de cegar", "luz", "manchas de luz", "ofuscar a vista". Dentro dessa isotopia os temas "luz", "verão", "de cegar" figurativizam-se em "noite clara", "listras brancas", "luz pela fresta das persianas", "anéis desenhados por toda parte". Pode-se notar ainda a construção de uma isotopia de traços semânticos de hábito, que irá se opor, na sequiência, à aventura inesperada vivida pelo personagem, criando uma oposição "dias iguais" versus "dias diferentes". Sua construção pode ser observada através dos lexemas: "ainda", "como sempre", "que de costume". Essa segunda isotopia, de hábito, pode ser identificada por "cozinha", representante de casa, lar, que é algo perene, e "mãe", figura também perene que pode indicar uma espécie de "porto seguro".

A recorrência de semas ligados à distração do menino é parte construtora da isotopia do prólogo da narrativa: "distraído e ausente", "Não sei o que há de errado com esse menino", "no que você está pensando, Robert? - em nada de especial", "Robert é apenas distraído". Cria-se com isso o sentido de que Robert tivesse facilidade para viajar, pelo fato de abster-se da realidade em suas distrações. Ao iniciar sua primeira "viagem" - entrar dentro da imagem da televisão e ir parar na Sibéria -, "sua

vista se escurece". Fecha-se, desse modo, a isotopia da luminosidade, para dar lugar ao tema "viagem", "aventura". 
Ao longo da narrativa, a cada lugar e época novos a que Robert chega, são construídos diferentes percursos temáticos e figurativos. A constante é que em cada passagem, a cada entrada de Robert em uma viagem nova há sempre um torpor e uma fuga. $\mathrm{Na}$ entrada para a primeira viagem, Robert foge da rotina, dos dias sempre iguais e sem graça. Nas entradas para as viagens seguintes, há sempre um elemento de pressão que o leva a se abstrair da realidade em que se encontra, como ser perseguido pela KGB russa ou fugir da polícia alemã que perseguia os comunistas. A constante é que Robert torna-se cada vez mais atento ou menos distraído.

São vários os estados de um sujeito dentro de uma narrativa. No caso de Robert, no início da narrativa ele encontra-se em conjunção com a distração, com a ignorância quanto à sua condição de sujeito-histórico e social, e no final da narrativa entra em conjunção com a perspicácia e a sabedoria, graças ao fato de ter se tornado um viajante (um fazer que o transformou).

O destinador-manipulador de Robert (responsável por seu fazer) é sua vontade de pertencer a um mundo diferente, que o retire da mesmice em que vive. Pode-se constatar isso quando a narrativa aponta: "Foi num dia como outro qualquer que Robert desapareceu" "Robert ainda está na cozinha, sentado em seu banquinho alto, como sempre" "Você vai se virar bem sozinho? pergunta a mãe antes de sair, como sempre" "Mas, de novo, Robert não está com fome, Robert não quer, Robert nunca está contente". Ele quer sair dessa situação, embora não seja um querer consciente ou muito menos verbalizado. O instrumento que tem para realizar esse fazer é seu problema de vista, que o faz enxergar manchas e, posteriormente, imagens dentro dessas manchas, até transportá-lo para dentro delas. Em vez de incomodá-lo, o problema lhe dá uma sensação agradável e o abstrai da realidade, criando para ele um mundo exclusivo. Robert é atraído por esse mundo de suas visões, e se deixa seduzir por ele. O menino aceita o contrato de manipulação, e passa a querer estar no mundo de suas visões. Ele crê que esse mundo seja bom para ele e o aceita.

No entanto, esse fazer tem um efeito inesperado para o menino, que é o de ser transportado para o mundo de visões e passar a fazer parte deste mundo. Robert continua, então, sendo manipulado por suas visões, que o levam a sete viagens diferentes, até que resolve assumir seu próprio destino de viagem, ao quebrar o contrato de manipulação e criar a imagem do lugar para onde quer voltar: a cozinha de sua casa.

Esse desejo o leva a um outro fazer-ser: Robert tem que se tornar um pintor, competente o bastante para produzir uma imagem perfeita da cozinha de onde saiu, para poder concentrar-se e voltar a ela. Ele agora é manipulado por esse desejo de retornar à sua própria realidade, e passa a trabalhar como aprendiz de pintor para adquirir essa competência pintar bem. Ela competência é modalizada pelo querer-fazer (voltar para casa) e o dever-fazer (voltar, pois Robert pensa em sua mãe, que deveria estar preocupada). Ao se tornar competente, capaz de um fazer, Robert realiza a perfórmance de voltar para casa. Durante a realização dessa perfórmance apropria-se dos valores descritivos "viagem", "casa dos pais", "conforto".

No nível narrativo, o sujeito Robert, em situação inicial, encontra-se em conjunção com a ignorância e em disjunção com o saber. Ao término de sua aventura, entra em conjunção com o saber: "O problema é que ele sabe demais. (...) Robert sabe 
muito bem o que o espera"(p. 259) Ele também se encontra, inicialmente, conjunto com o tédio, pois não gosta do mundo em que vive, por isso está sempre "ausente" (nas palavras de sua professora). Ao término da narrativa, após entrar em conjunção com as aventuras que viveu ao longo do tempo, pode-se entender que ele não estará mais ausente de seu mundo, justamente por agora possuir saberes que o fazem diferente de todos e que lhe retiraram a sensação de tédio e mesmice.

\section{REFERÊNCIAS BIBLIOGRÁFICAS}

BARROS, Diana Luz Pessoa de. Teoria Semiótica do Texto. 4. ed. São Paulo: Ática, 2003.

BERTRAND, Denis. Caminhos da Semiótica Literária. Trad. do Grupo CASA. Bauru, SP: EDUSC, 2003.

CORTINA, A. Semiótica e leitura: os leitores de Harry Potter. In: CORTINA, A.; MARCHEZAN, R. C. (Org.). Razões e sensibilidades: a semiótica em foco.

Araraquara: Cultura Editorial / Laboratório Editorial, 2004, p. 153-190.

ENZENSBERGER, Hans Magnus. Por onde você andou, Robert? Trad. de João Azenha Jr. São Paulo: Companhia das Letras, 1999.

FIORIN, José Luiz. Elementos de Análise do Discurso. 8. ed. São Paulo: Contexto, 2000.

GOULEMOT, Jean-Marie. Da leitura como produção de sentidos. In: CHARTIER, Roger. Práticas da Leitura. Trad. de Cristiane Nascimento. 2. ed. São Paulo:

Estação Liberdade, 2001.

\section{Como citar este artigo:}

NORONHA-TADDEI , Ana Carolina Cortez. A viagem de um leitor: uma investigação semiótica do processo de leitura. Estudos Semióticos, Número 1, São Paulo, 2005. Disponível em <www.fflch.usp.br/dl/semiotica/es > . Acesso em "dia/mês/ano". 